\title{
BMJ Open Patient-physician mistrust and violence against physicians in Guangdong Province, China: a qualitative study
}

\author{
Joseph D Tucker, ${ }^{1,2,3,4}$ Yu Cheng, ${ }^{3,4}$ Bonnie Wong, ${ }^{2,5}$ Ni Gong, ${ }^{3,4}$ Jing-Bao Nie, ${ }^{6}$ \\ Wei Zhu, ${ }^{7}$ Megan M McLaughlin, ${ }^{8}$ Ruishi Xie, ${ }^{9}$ Yinghui Deng, ${ }^{9}$ Meijin Huang, ${ }^{9}$ \\ William C W Wong, ${ }^{10,11}$ Ping Lan, ${ }^{9}$ Huanliang Liu, ${ }^{9,12}$ Wei Miao, ${ }^{9}$ \\ Arthur Kleinman, ${ }^{13}$ and the Patient-Physician Trust Project Team
}

To cite: Tucker JD, Cheng Y, Wong B, et al. Patientphysician mistrust and violence against physicians in Guangdong Province, China: a qualitative study. BMJ Open 2015;5:e008221.

doi:10.1136/bmjopen-2015008221

- Prepublication history and additional material is available. To view please visit the journal (http://dx.doi.org/ 10.1136/bmjopen-2015008221).

JDT, YC and BW contributed equally.

Received 17 March 2015 Revised 6 August 2015 Accepted 17 September 2015

CrossMark

For numbered affiliations see end of article.

Correspondence to Dr Joseph D Tucker; jdtucker@med.unc.edu

\section{ABSTRACT}

Objective: To better understand the origins, manifestations and current policy responses to patientphysician mistrust in China.

Design: Qualitative study using in-depth interviews focused on personal experiences of patient-physician mistrust and trust.

Setting: Guangdong Province, China.

Participants: One hundred and sixty patients, patient family members, physicians, nurses and hospital administrators at seven hospitals varying in type, geography and stages of achieving goals of health reform. These interviews included purposive selection of individuals who had experienced both trustful and mistrustful patient-physician relationships.

Results: One of the most prominent forces driving patient-physician mistrust was a patient perception of injustice within the medical sphere, related to profit mongering, knowledge imbalances and physician conflicts of interest. Individual physicians, departments and hospitals were explicitly incentivised to generate revenue without evaluation of caregiving. Physicians did not receive training in negotiating medical disputes or humanistic principles that underpin caregiving. Patient-physician mistrust precipitated medical disputes leading to the following outcomes: nonresolution with patient resentment towards physicians; violent resolution such as physical and verbal attacks against physicians; and non-violent resolution such as hospital-mediated dispute resolution. Policy responses to violence included increased hospital security forces, which inadvertently fuelled mistrust. Instead of encouraging communication that facilitated resolution, medical disputes sometimes ignited a vicious cycle leading to mob violence. However, patient-physician interactions at one hospital that has implemented a primary care model embodying health reform goals showed improved patient-physician trust.

Conclusions: The blind pursuit of financial profits at a systems level has eroded patient-physician trust in China. Restructuring incentives, reforming medical education and promoting caregiving are pathways towards restoring trust. Assessing and valuing the quality of caregiving is essential for transitioning away from entrenched profit-focused models. Moral, in

\section{Strengths and limitations of this study}

- Our qualitative data were collected from a range of hospital types, locations and stages of achieving the goals of health reform.

- One of the most prominent forces driving patient-physician mistrust was a patient perception of injustice within hospitals.

- Individual physicians, departments and hospitals were explicitly incentivised to generate revenue.

- Patient-physician interactions at one hospital that has implemented a primary care model embodying health reform goals showed improved patient-physician trust.

- Further research and policy attention are needed to improve patient-physician trust.

addition to regulatory and legal, responses are urgently needed to restore trust.

\section{INTRODUCTION}

A seeker of wisdom asked Confucius about the essential elements of governing a state. Confucius replied, "It is to provide food, protect people with weapons, and gain trust from people." The seeker asked further which should be abandoned first if the state is forced to choose between foregoing food, weapons or trust. Confucius advised to abandon weapons first, then food. However, he advised never to abandon trust. $\mathrm{He}$ explained, "Trust is more important than life itself." This story suggests that trust is important within Chinese social relationships.

Patient-physician trust is an implicit, fundamental building block of clinical medicine. A physician's trust of his patients and a patient's trust of his physician are inherently related, and both are crucial for healthcare partnerships. Reciprocal trust establishes a 
moral dimension to healing that is related to, but also distinct from, the biomedical aspects of eradicating disease. However, the local moral worlds within Chinese hospitals are now fraught with tension and the growing friction between patients and physicians has resulted in verbal abuse, threats and physical assault. ${ }^{1}$ Medical mobs, called yinao, regularly protest at hospitals or harass hospital administrators in exchange for money. ${ }^{2}$ In 2011, a 10 province survey in China found that over half of the physicians had been verbally abused, one-third had been threatened and $3.4 \%$ had been physically assaulted by patients in the past 12 months. ${ }^{3}$ The level of violence observed in China is more common compared with violence against medical professionals in other countries. ${ }^{2}$

Responding to the worsening patient-physician mistrust, national Chinese government leaders have identified this mistrust as a major problem. ${ }^{4}$ Policy responses to date have focused on adding security staff to hospitals and outlawing hongbao (red packets given as gifts) and related stopgap measures. ${ }^{5}$ Although several individuals have sounded calls to action, ${ }^{1}{ }^{2} 6$ current understanding is based on limited empirical data. ${ }^{7}$ Deeper investigations that examine the origins, manifestations and policy responses to patient-physician mistrust are needed. We undertook this qualitative research to better understand patient-physician mistrust and to create an evidencebased foundation for restoring trust.

\section{METHODS}

Our study was implemented at seven hospitals (table 1) in Guangdong Province, a province that recorded 25000 medical disputes in 2013. ${ }^{8}$ Further data on the nature of these medical disputes and how this province compares with other provinces are not published. This province was chosen because of the diversity of field sites (Western and Traditional Chinese Medicine, urban and rural, and various stages of achieving health reform goals) and access to hospital leaders. Goals of ongoing Chinese health reform focus on improving the primary care delivery system, piloting hospital reform, improving access to healthcare and public health services, and establishing a national essential medicines system. ${ }^{9}$ The hospital that most closely achieved the core principles of health reform had flat fees (inclusive of diagnostics and 7 days of medication), strict policies prohibiting gifts of any kind from pharmaceutical representatives or patients, and higher physician salaries. These incentive changes were possible because of substantial support from the local government and hospital administrators from Hong Kong University.

The research included participant observation and in-depth interviews with patients, patient families, physicians, nurses and hospital administrators. Participant observation was overt within clinical settings. One researcher spent evenings in the hospital and stayed overnight in order to facilitate frank discussions.
Participant observations were recorded and used as formative data to revise the in-depth interview guide. Hospital administrators included a range of leaders directly responsible for creating or monitoring hospital policies related to patient-physician disputes. Although violence has been reported against nurses and other health professionals, we focused on patient-physician relationships because physicians have greater power within hospital systems to mobilise change. We purposively sampled participants to include younger and older physicians, inpatient and outpatient experiences, and a broad range of patient-physician relationships. Purposive sampling domains were qualitatively assessed. Our goal was to identify patient-physician relationships that were mistrustful as well as relationships that were trustful. The interview guide was developed on the basis of five key informant interviews with hospital administrators, observations recorded from participant observations at each hospital, and a literature review of qualitative patient-physician trust (see online supplementary material). We continued to conduct interviews until thematic saturation was reached at each site.

Data collection was conducted between June and September 2013. First, hospital administrators were approached by study staff about interviewing participants, and then individual physicians were contacted through the medical affairs office. Participant observation was conducted by the study staff to establish rapport with physicians, nurses and patients. Some patients were identified through physicians and others were identified and contacted directly by the study staff after a period of participant observation. In-depth interviews used a semistructured interview guide of open-ended questions. Patients were asked to describe their current health status and their interaction with the healthcare system, including why they chose the hospital or doctor, their feelings regarding that hospital or the care provided, their interactions with physicians, and their thoughts regarding their own patient-physician interactions in China. Physicians and healthcare practitioners were asked to describe their training, their daily work experience, positive and negative interactions with patients, and thoughts about their medical career. Both patients and physicians were asked specifically regarding medical disputes, local media portrayal of doctors, security in hospitals and healthcare costs. Administrators were asked to describe their training and professional experience, their engagement with medical disputes, the hospital finance and fee models, and their general thoughts regarding patient-physician relationships in China.

Interviews were conducted in Chinese by an anthropologist accompanied by a research assistant who took notes. Participants were offered a small gift as an inducement to participate. Each interview lasted 45-90 min. When possible, interviews were conducted in private spaces to protect the confidentiality of interview participants. Interviewers obtained written informed consent from all participants and interviews were audiotaped if 
Table 1 Overview of sampling at each hospital

\begin{tabular}{|c|c|c|c|c|c|c|}
\hline & Doctors & Nurses & Administrators & Patients & Family members & Total \\
\hline $\begin{array}{l}\text { Hospital } 1 \\
\text { Tertiary referral hospital; } \\
\text { General hospital }\end{array}$ & 10 & 5 & 3 & 12 & 4 & 34 \\
\hline $\begin{array}{l}\text { Hospital } 2 \\
\text { Western running mechanism; } \\
\text { Hospital reform target site; } \\
\text { Tertiary referral hospital }\end{array}$ & 11 & 4 & 4 & 11 & 4 & 34 \\
\hline $\begin{array}{l}\text { Hospital } 3 \\
\text { Tertiary referral hospital; } \\
\text { Traditional Chinese Medicine Hospital }\end{array}$ & 10 & 4 & 4 & 11 & 4 & 33 \\
\hline $\begin{array}{l}\text { Hospital } 4 \\
\text { County-level tertiary referral hospital; } \\
\text { General hospital }\end{array}$ & 10 & 4 & 3 & 11 & 2 & 30 \\
\hline $\begin{array}{l}\text { Hospital } 5 \\
\text { County-level grade II level A hospital; } \\
\text { General hospital }\end{array}$ & 9 & 4 & 4 & 10 & 2 & 29 \\
\hline $\begin{array}{l}\text { Hospital } 6 \\
\text { District-level urban hospital }\end{array}$ & 3 & 0 & 3 & 0 & 0 & 3 \\
\hline $\begin{array}{l}\text { Hospital } 7 \\
\text { Integrated paediatric hospital }\end{array}$ & 1 & 0 & 3 & 0 & 0 & 3 \\
\hline Total & 54 & 21 & 24 & 55 & 16 & 166 \\
\hline
\end{tabular}

participants provided consent. If participants declined audio recording, written notes were used for analysis. All audiotaped interviews were transcribed into Mandarin and analysed. We used grounded theory ${ }^{10}$ informed by Kleinman's ${ }^{11}{ }^{12}$ concept of local moral worlds to structure the analysis. By local moral worlds, we focused on what was at stake for doctors in their clinical settings and how that contrasted with what was at stake for patients and families. ${ }^{12}$ These two theories were identified a priori on the basis of their relevance to the moral context of health in China. Previous research on patient-physician relationships in China has not focused on the moral dimensions. Coding was done in Chinese using Atlas ti (V.7.0, Berlin, Germany). The coding guide was developed by three individuals based on examining 10 interviews. Emergent themes were identified and expanded into sections on origins, manifestations and policy responses to patient-physician mistrust.

\section{RESULTS}

We interviewed 166 individuals about patient-physician trust and mistrust (table 1). Our data highlighted some of the origins, outcomes and policy responses to

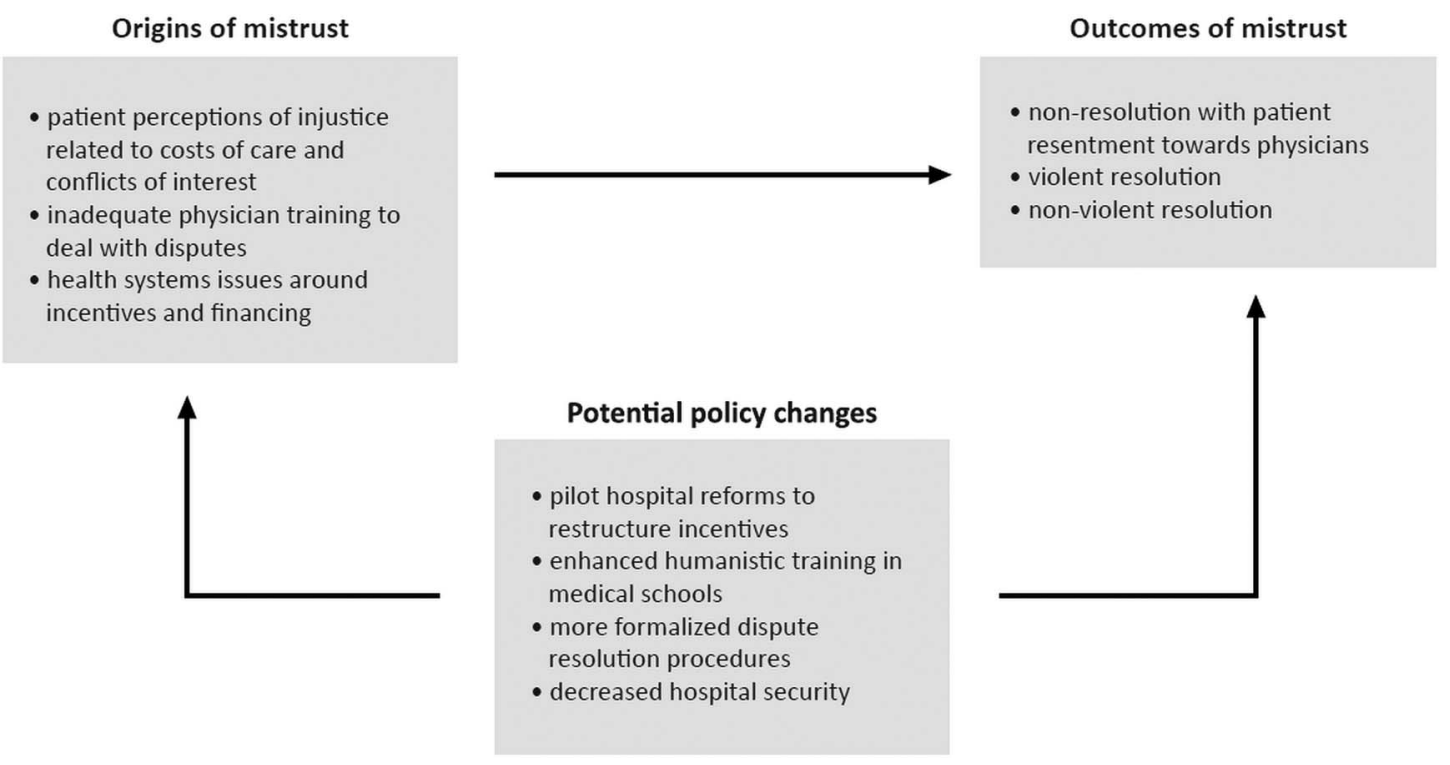

Figure 1 Origins, outcomes and policy responses of patient-physician mistrust. 
Table 2 Quotations supporting origins of patient-physician mistrust

Perceptions of injustice driving patient-
physician mistrust

High expectations from patients

Physicians lack training in medical communication and humanities

\section{Quotes}

(1) "Now everything is guided by economics. For physicians, hospital salaries can't come close to matching money from kickbacks and commissions. Maybe because his wallet grows, he is willing to engage in practices that violate his own professional ethics so that he can increase his own profits."-Patient (2) "[To a physician, the patient's] life is only worth several hundred yuan [tens of GBP]. In China, a person's life is just not worth that much. So as a physician if you save things that do not have that much worth, then your income will be low."-Physician

(3) "You will find that when some patients see the doctor, they carry with them an extremely distrustful, hostile, and negative tone of speaking. These patients lay it out: newspapers are talking about the violence, hospitals are not to be trusted, and doctors are the worst. If you see a hundred patients and only see one distrustful patient, it matters. It slowly influences your perception of patients."-Physician

(1) "The biggest problem is the information between patients and physicians is asymmetric. Physicians have too much information and patients have too little. And physicians' information is very systematic, while patients' information is disorganized. This information inequality can cause many conflicts."Physician

(1) "[Health professional education] It's just taught according to the book line by line, it's very rigid and dogmatic. For example, patient-doctor communication isn't sufficient. Actually at the bedside we learn a lot of these kinds of communication skills. But the kinds of communication skills we were taught in school are not the kinds of skills we can apply."-Nurse

(2) "Resolving the physical illness makes the patient feel satisfied. But if you're also able to deal with the psychological issues, it would make everyone better off. There are some people whose medical skills you can't deny but their temperament and communication skills impede their work."-Physician patient-physician mistrust in China (figure 1). The origins of patient-physician mistrust were rooted in strong perceptions of injustice (table 2). Patients felt that drug and overall medical costs were inflated and clinical decisions about diagnostic tests and drug prescriptions were skewed towards maximising revenue instead of improving outcomes (table 2). One patient remarked that "Now everything is guided by economics. For physicians, hospital salaries can't come close to matching money from kickbacks and commissions." Patients and physicians described how patients with lifethreatening illnesses who presented to the emergency department without sufficient funds were refused critical care. The essential motive of physicians to prioritise healing patients was threatened by a wide range of nonsalary incentives, including the following: indirect favours and all-expenses paid trips to tourist sites and conferences; incentives from hospitals and clinical departments to generate revenue; direct cash payments from pharmaceutical companies based on the number of branded drugs prescribed; favours, cash and gifts as part of hongbao from patients. In the hospital context, red packets are cash gifts given to physicians in an attempt to assure high-quality care. However, patients reported heightened expectations after giving red packets that subsequently distorted relationships and inferred that good health outcomes could be purchased. These practices often contributed to unrealistically high expectations from patients and their families that led to disappointment after poor outcomes (table 2).

In addition to patients' perceptions of unfairness, physicians also reported injustices within the medical system. Physicians noted intense workloads (eg, seeing 50 outpatients within a $4 \mathrm{~h}$ outpatient clinic shift) and pressures from within the hospital to generate revenue in the face of low salary, high patient expectations and sensationalist reports from mass media (table 2). Moreover, physicians reported inadequate training to deal with patient disputes. The conventional medical curriculum in China focused on biomedical didactics rather than humanistic experiential training. Physicians also noted that the training system resulted in a limited number of subspecialised experts clustered in urban tertiary care settings transiently evaluating a large volume of patients rather than a larger number of primary care doctors longitudinally caring for a smaller volume of patients. Moral dimensions of medicine such as caregiving, conflicts of interest, professionalism and medical ethics were not included in medical training. We define caregiving as providing cognitive, behavioural, emotional and moral support. Technical biomedical competence was prioritised over caregiving and 
Table 3 Quotations supporting manifestations of patient-physician mistrust

\section{Theme}

Non-resolution with residual patient resentment towards hospitals

Violent resolution of a medical dispute

\section{Non-violent resolution through informal} mechanisms

\section{Quotes}

(1) "There are several reasons for this [resentment]. One is that in China taking the legal route is too complex. Second, a patient considers fairness. He worries about whether or not health institutions cover up for each other. Third, there are certainly some people instigating it, including medical mobs at our hospital. Every time it's the same several people and some are professional medical mobs. In China, a lawsuit is really inconvenient. It might be able to resolve the problem, but the patient can't necessarily wait that long. Finally, if the patient goes and stirs up trouble and sees that the government again comes out and helps him resolve the problem, he will feel that choosing this route is best, as a result it encourages this practice."-Physician

(2) "At the beginning he said that he wanted our associate dean to come out and apologize to him. We gave the patient an explanation, but he continued to make a fuss. The patient later made requests that made us not know whether to laugh or cry. He said, 'All I want is to have your director to kneel down and apologize in public. That is all I want, nothing else.' Then one of our colleagues from the medical affairs department became angry and said, 'If you say this then there's nothing we can do. We can't go on discussing."-Administrator (3) "The physicians, nurses, no one was able to mediate between the upset patient and the hospital. These people said they wanted to see the director. They also organized a medical mob and held banners at the hospital. They said the hospital treated human life as worthless. They made it so the doctor was not able to continue seeing other patients because of the dispute. The patient's whole village came."-Physician

(1) "But I don't know why they still have not taken the normal channel. Later when the family members forced the hospital to pay the money, at once he (the patient) climbed to the fourth floor and jumped."-Nurse

(1) "[The patient affairs department] might go communicate with the patient and give the patient a platform for communication because many patients today feel that doctors are too remote. I file a complaint about you but you don't fear complaints. Actually patient affairs has this kind of function. If doctors and nurses do not treat a patient well, this complaint is valuable. Then our hospital would definitely give a warning to the relevant staff, the relevant doctors and nurses, or even take disciplinary action or make a dismissal. This can definitely happen."-Physician

(2) "In our institution's [hospital with a new primary care model] guidelines we strictly prohibit physicians from accepting red packets and money from pharmaceutical representatives. And our appointment system schedule has to a certain extent helped mitigate conflicts."-Physician

(3) "Here [hospital with a new primary care model] it's organizational reform. We are putting more emphasis on patient satisfaction, encouraging a patient service mentality, aligning more with international standards, so we are demanding more and more from ourselves."-Physician empathy for patients both in medical training and in clinical practice.

Patient-physician mistrust led to anger enacted in medical disputes resulting in three main outcomesnon-resolution with patient resentment towards physicians, violent resolution and non-violent resolution (table 3, figure 2). Anger and perceptions of unfairness were initially communicated to family and friends. Social media and kinship networks then facilitated the organisation of public protests at hospitals. Smaller protests (fewer than 15 people) were organised by family members of the patients. Larger protests (greater than 15 people) were organised by medical mobs. Violent resolutions included verbal abuse, threats against physicians and physical violence resulting in injuries and deaths. Some patients successfully negotiated the hospital system to broker an informal resolution and receive a sum of money (figure 2). There was a strong reluctance to use legal means to resolve medical disputes. This reluctance was ascribed to the complexity of filing lawsuits and the relatively underdeveloped legal system poorly equipped to respond (table 3 ).

Several policy responses to violence against physicians emerged (table 4). Hospital security forces were deployed at several hospitals with the intention of making hospitals safer. However, security staff and guards within hospitals made patients and their families feel insecure and upset with hospital systems. Increased 


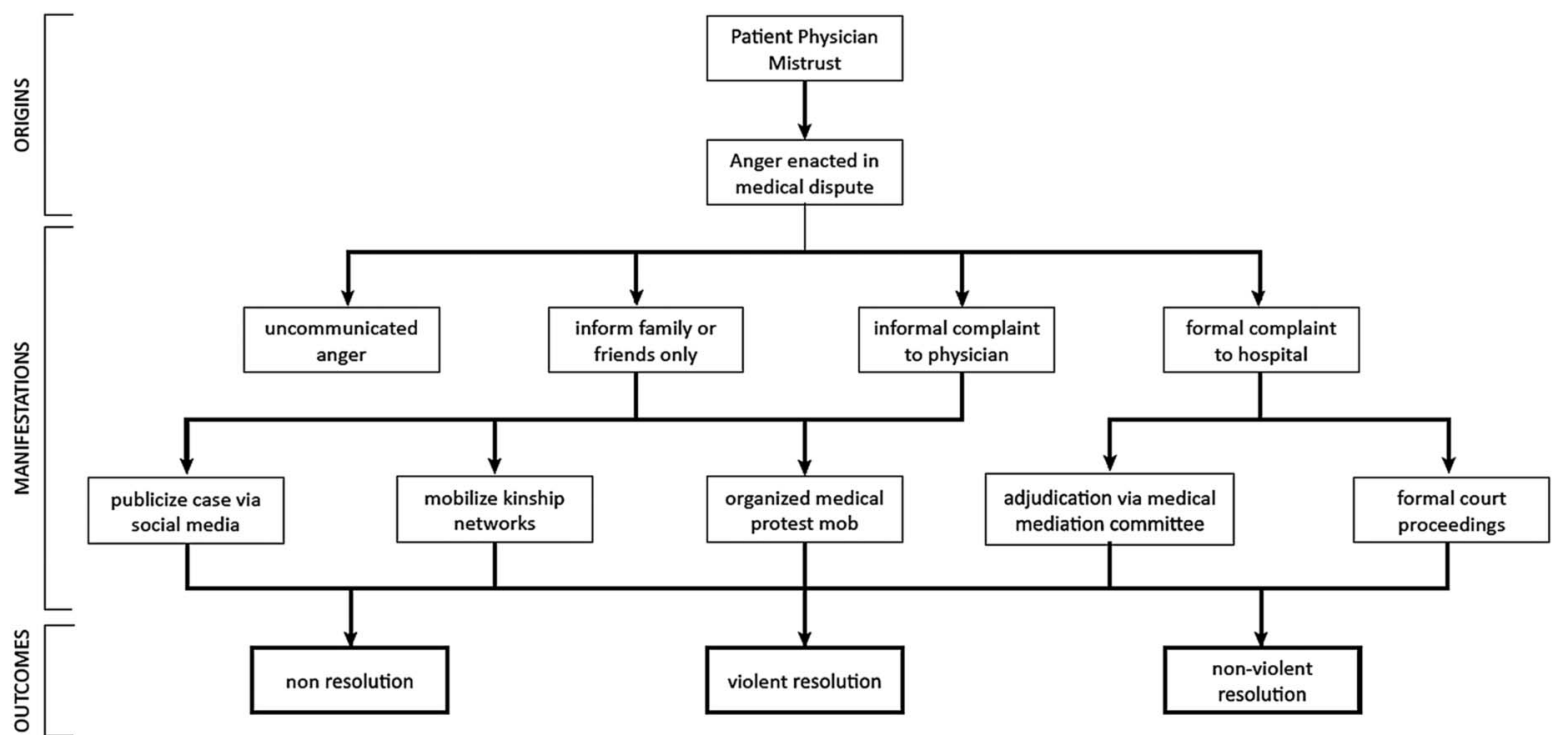

Figure 2 Schematic of pathways from patient-physician mistrust to outcomes of medical disputes.

media attention on medical disputes also reinforced mistrust (table 4). Greater security staff more strictly enforced family visit restrictions in hospitals, worsening patient medical experience. This led to a vicious cycle with the unintended consequence of worsening mistrust (figure 3). Several hospitals also piloted "patient suggestion boxes", more formalised dispute resolution within medical affairs departments, and related measures to address disputes.

Non-violent dispute resolutions were more common within a new model of primary care consistent with core principles of health reform (table 4, figure 1). At University of Hong Kong-Shenzhen Hospital (HKU-SZH), doctors were expected to prescribe regimens according to their ability and judgement, "keeping oneself far from all intentional ill-doing and all seduction." The hospital believed that healthcare is not a commodity and quality care requires investment. HKU-SZH is a joint venture between University of Hong Kong and the Shenzhen Municipal Government. Medical staff were remunerated at a salary comparable to other professionals of similar standing. Medical staff bonuses were not linked to the income of individual departments. The hospital has a strict zero tolerance policy on the acceptance of bribes, favours and any other in-kind benefits. The health system was set up to optimise patientcentred experiences and streamline the process of receiving high-quality care from the perspective of patients. Physicians have $15 \mathrm{~min}$ of protected time for each initial appointment with patients. To make this financially viable, the registration fee to see a doctor is 100 renminbi (RMB) ( $£ 10.60 \mathrm{GBP})$ and this includes a consultation and preliminary diagnostics. Seven days of medication costs an additional $100 \mathrm{RMB}$ (£10.60 GBP).

Patients within this system reported higher levels of trust, in part because they were confident that physicians did not receive any non-salary payments and were focused on patient-centred care. In turn, physicians reported greater levels of trust in their patients, as patients who were willing to pay higher initial fees also had an understanding for the motivations behind the flat-fee payment model. Administrators in this hospital noted that longer clinical visit times, physician training and detailed evaluation, transparent means of addressing patient complaints and suggestions, and flat fees for diagnostics and medications contributed to patient-physician trust.

\section{DISCUSSION}

Our study found that patient perceptions of injustice related to the costs of care and conflicts of interest, inadequate physician training and health systems factors contributed to patient-physician mistrust (figure 1). Patient-physician interactions at one hospital that has implemented a primary care model embodying health reform goals showed improved patient-physician trust. The crisis of widening patient-physician mistrust in China revealed through this empirical research extends previous theoretical research. ${ }^{23}{ }^{13}{ }^{14}$ While patient-physician mistrust has been noted among minorities in the USA, ${ }^{15}{ }^{16}$ it has become a common part of the Chinese patient experience. Although similar research in low income countries is lacking, ${ }^{17}$ our findings are consistent with research on patient-physician mistrust in Pakistan $^{18}$ and India. ${ }^{19}$

Our data suggest that patient perceptions of societal injustice and the commercialisation of medicine play a major role in the development of patient-physician mistrust in China. Hospitals systematically refuse care to poor patients and financially devastate families that have prolonged illness. Rudimentary health insurance schemes alongside an underdeveloped legal infrastructure provide few options for the sick who cannot afford health services. ${ }^{9}$ Focusing on financial rather than humanistic aspects of 
Table 4 Quotations supporting policy responses to patient-physician mistrust

Theme
Increased hospital security forces inadvertently
precipite mistrust

precipitate mistrust

Increased media attention reinforces mistrust between physicians and patients

A hospital using a new primary care model has started the process of gradually restoring patient-physician trust

\section{Quotes}

(1) "I don't really like this feeling of having the security guards making inspections. I understand why the hospitals are doing this now, they're worried about patients stirring up trouble. But the security guards are walking back and forth, and sometimes when I take a walk in the hallway I run into them. I have the feeling of a prisoner being let out to exercise. This makes me feel very uncomfortable. I feel like I am not free and I'm being watched."-Patient

(1) "If reported incorrectly, media portrayals of medical disputes tarnish the image of physicians. Increasingly the media holds responsibility for conflicts between physicians and patients. Of course, many common people don't really understand, and then the media exaggerates to make it look more serious. For example, expectations about the cost and ability to cure an illness should be reasonable. They can't be too high. I think the media should disseminate medical knowledge. When a dispute occurs, the media should report it objectively. Before reporting, they should interview physicians, understand the situation a little. Sometimes the media reports are inaccurate and its clear the media doesn't understand medicine."-Physician

(2) "Some [media stories] are true, but some are taken out of context. The media goes and amplifies one point of view. Because the media always wants to find a flashpoint, a highlight, to attract people to read or watch the report. There certainly is this kind of news report, but you need to look at whether the perspective is balanced. The way the media reports many things is not from a balanced perspective. One reason is that they don't have this kind of specialized knowledge, and second, I think they write with a certain aim. Some media stories are real, but some media really carries its own purpose. When the media provokes negative emotions in the public, it is difficult to control. Reading about so many terrible incidents, if you see something, you will think there is a problem."-Patient

(3) "They [patients] often see too many negative news. Basically every day the news on TV always has something about medical treatment scandals, about this type of thing, or else it's a dispute between a patient and doctor. Many people just take the side of the media. After an exposé, the common people just think that many [doctors or hospitals] are not trustworthy."-Physician

(1) "I think general practitioners can completely solve this problem [of patients crowding large hospitals]. If these things [minor medical issues] are given to general practitioners to handle, then patients won't need to crowd the large hospitals, then the large hospitals probably won't have to call on the big physicians in each specialty so much, and they will have more time and energy to do more specialized [cases]. I think general practitioners ought to have an even greater function."-Physician

(2) "It's not that I will just prescribe whatever medication you want me to prescribe, rather I will prescribe whatever medication your condition requires...I don't need to order so many diagnostic tests. Second, pharmaceutical misuse is a big part of it. Third, prescribing medications and ordering diagnostic tests affects the cost problem. If I reduce the patient's expenses, he is also very satisfied."Physician

(3) "Compared to other hospitals in China, the salaries for physicians at this hospital [the primary care model] are quite good, even considering that doctors in some of the large hospitals receive money under the table [red packets or payments from pharmaceutical representatives]. Altogether the salary here has been carefully thought through [by the administration], it's a dignified salary. The salary structure incentivises quality performance."Physician 


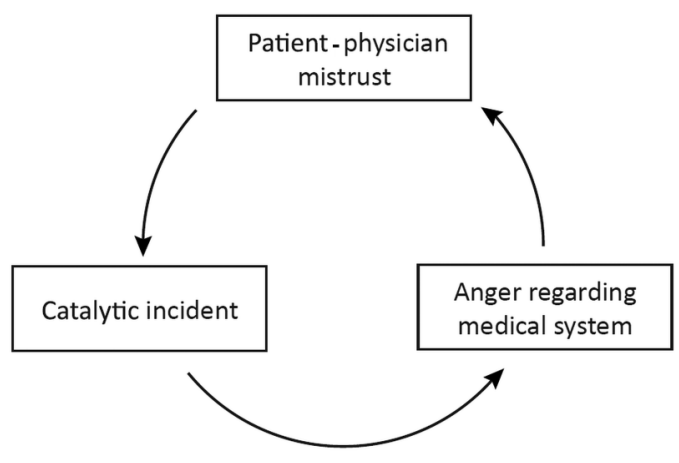

Figure 3 Vicious cycle of unintended consequences resulting from mistrust and medical disputes.

medicine has eroded patient-physician trust in the USA, ${ }^{20-22}$ the $\mathrm{UK}^{23}$ and other settings. ${ }^{17}$ However, Chinese physicians are directly and indirectly paid by non-employers to a far greater extent than physicians in other countries. ${ }^{9}{ }^{24}$ Limited government financial support to hospitals (often less than $15 \%$ of the overall budget) alongside low physician salaries encourage these structural distortions. $^{25}$ The Commission on Health and Family Planning in China announced that it would ban all red packets given to physicians, ${ }^{26}$ but broader health systems innovations are needed to fundamentally realign incentives.

We found that physician training lacked core humanistic components that nurture empathy and caregiving. The rituals, curriculum and relationships of medical training shape physician values and professionalism. ${ }^{27} 28$ Additional preclinical and clinical training could equip junior physicians with the skills required to address disputes with patients, including negotiating and reporting disputes, navigating conflicts of interest, applying principles of medical ethics, empathising with patients and families and apologising for errors. ${ }^{29}$ Outside of China, results from humanistic medical education initiatives suggest that nurturing these components promotes patient-physician trust. ${ }^{30}$

We found that interactions at the hospital implementing health reform goals improved patient-physician trust. Although these models are relatively new, they suggest that restructuring incentives at the hospital level may help restore patient-physician trust. This finding is consistent with other research in China showing that health reform pilots have been associated with higher levels of patient and physician satisfaction ${ }^{31}$ but contradicts ecological data suggesting a link between health reform and increased violence at Chinese hospitals. ${ }^{32} 33$ These ecological data would not account for the relatively high level of violence against physicians observed in many urban hospital settings in which health reform has been incomplete or slow. Our data provide further empirical evidence that accelerating health reform implementation may promote patient-physician trust.

While we focused on patient-physician mistrust, interpersonal mistrust in China extends beyond the medical sphere and has been observed in a wide range of other relationships, including student-teacher, ${ }^{34}$ worker-employer ${ }^{35}$ and citizen-leader. ${ }^{36}$ The recent infant milk powder contaminant scandal $^{37}$ reinforces such interpersonal mistrust between the powerless and the powerful. However, a broader analysis of interpersonal mistrust in China was beyond the scope of this research.

Our research has several limitations. First, we limited data collection to one Chinese province. However, Guangdong is one of the largest provinces in China and draws migrants from across the country. We also used a purposive sampling strategy to ensure that hospitals in various stages of health reform, geographies and clinical contexts were captured. Further research in other provinces and regions is necessary to improve patient-physician trust in China. Second, our study was cross-sectional and causal inferences should be viewed with caution. Third, our investigation focused on referral centres in urban and semiurban settings, without examining township-level health centres. Fourth, our investigation was not focused on the underdeveloped medical malpractice system in China. ${ }^{38}$ Gradual advances in dispute resolution and the rule of law can also help restore patient-physician trust. Finally, our research is qualitative and not meant to be representative. The purpose of undertaking this qualitative research was to obtain rich local descriptions of patientphysician mistrust and trust in order to inform reform.

Recent policy reforms in China have focused on preventing violence against physicians instead of restoring patient-physician trust. Both President Xi Jinping and the Health and Family Planning Commissioner Li Bin explicitly mentioned violence against physicians during the 2014 National People's Congress, ${ }^{39}$ emphasising strict punishment of offenders in accordance with Chinese laws and regulations. Yet the moral crisis that our study revealed in Chinese healthcare demands a legal and regulatory response as well as a moral one. The Chinese phrase "zhibiao bu zhiben" means treating the symptoms and not the disease. Cracking down on violence and enhancing security measures are unlikely to fundamentally alter patient-physician mistrust and may inadvertently undermine trust.

Our research suggests three policy actions to restore patient-physician trust in China. First, hospital incentives must be restructured and health reform accelerated at the hospital level to emphasise that primary care is essential. Physician financial conflicts of interest must be directly acknowledged and reported in order to gradually restore trust in physicians and the healthcare system at large. Second, medical education would benefit from greater attention to the humanities, including clinical training focused on patient-physician communication, ethics, professionalism and dispute resolution. ${ }^{40}$ Finally, caregiving must be formally and informally nurtured. The sharp fissures between patients and physicians need to be broached in their most basic physical, emotional and cognitive terms. Patients and 
their families who have suffered at the hands of the medical system must be willing to negotiate and seek non-violent solutions. Physicians who have been involved in such suffering must be willing to apologise to patient families and accept reasonable consequences for medical error. Meanwhile, physicians and hospital administrators must step up to serve as moral agents in order to rebuild patient-physician trust.

\section{Author affiliations}

${ }^{1}$ Department of Medicine, University of North Carolina at Chapel Hill School of Medicine, Chapel Hill, North Carolina, USA

${ }^{2}$ UNC Project-China Office, Guangdong Provincial STD Control Center, Guangzhou, Guangdong, China

${ }^{3}$ School of Sociology and Anthropology, Sun Yat-sen University, Guangzhou, Guangdong, China

${ }^{4}$ Center for Medical Humanities, Zhongshan School of Medicine, Sun Yat-sen University, Guangzhou, China

${ }^{5}$ School of Medicine, Stanford University, Palo Alto, California, USA

${ }^{6}$ University of Otago, Dunedin, New Zealand

${ }^{7}$ School of Medicine, Fudan University, Shanghai, China

${ }^{8}$ Harvard Medical School, Harvard University, Boston, Massachusetts, USA

${ }^{9}$ The Sixth Affiliated Hospital, Sun Yat-sen University, Guangzhou,

Guangdong, China

${ }^{10}$ University of Hong Kong, Ap Lei Chau, Hong Kong

${ }^{11}$ University of Hong Kong-Shenzhen Hospital, Shenzhen, Guangdong, China

${ }^{12}$ Guangdong Institute of Gastroenterology, Sun Yat-sen University,

Guangzhou, Guangdong, China

${ }^{13}$ Harvard Asia Center, Harvard University, Cambridge, Massachusetts, USA

Contributors JDT led the data analysis and manuscript writing. YC led the fieldwork supervision. JDT, J-BN, AK and WZ conceived of the study. HL, WCWW, YD, PL and WM also contributed to the study design. NG, J-BN and BW collected the data. Figures and literature search were led by BW with assistance from NG and MMM. WCWW coordinated the field research at one site and $\mathrm{HL}$ coordinated the fieldwork at other sites. MH, YD, PL and RX helped arrange interviews and obtain approvals from local hospitals. All the authors made contributions to the manuscript and approved the final version.

Funding This research was supported by grants from the Harvard China Fund and the China Medical Board.

Competing interests None declared.

Patient consent Obtained.

Ethics approval All study procedures were approved by the Institutional Review Boards at Sun Yat-sen University, Harvard University, the University of Otago and the University of North Carolina at Chapel Hill.

Provenance and peer review Not commissioned; externally peer reviewed.

Data sharing statement Complete transcribed data available with the approval of respective IRBs and study PIs.

Open Access This is an Open Access article distributed in accordance with the Creative Commons Attribution Non Commercial (CC BY-NC 4.0) license, which permits others to distribute, remix, adapt, build upon this work noncommercially, and license their derivative works on different terms, provided the original work is properly cited and the use is non-commercial. See: http:// creativecommons.org/licenses/by-nc/4.0/

\section{REFERENCES}

1. [No authors listed]. Ending violence against doctors in China. Lancet 2012;379:1764

2. Hesketh T, Wu D, Mao L, et al. Violence against doctors in China. BMJ 2012;345:e5730.

3. Zhang $X$, Sleeboom-Faulkner M. Tensions between medical professionals and patients in mainland China. Camb Q Healthc Ethics 2011;20:458-65.
4. No authors listed]. Violence against doctors: Why China? Why now? What next? Lancet 2014;383:1013.

5. Guidance on strengthening hospital security $2013 ; 28$. Chinese Government Public Information Online. http://govinfo.nlc.gov.cn/ scsfz/xxgk/scswst/201311/t20131122_4286649.shtml?classid=451 (accessed 1 Oct 2015).

6. Zhong N. Guangzhou doctor's last year salary is 46,000 ; actual salary is 190,000 . Sohu News, 2014. http://business.sohu.com/ 20140305/n396102194.shtml (accessed 1 Oct 2015).

7. Tam W. Health care reform and patients' trust in physicians in Urban Beijing. China Q 2012;211:827-43.

8. Yang X. Medical disputes and medical mobs in three cities. Yangcheng Evening News 2014.

9. Yip WC, Hsiao W, Meng Q, et al. Realignment of incentives for health-care providers in China. Lancet 2010;375:1120-30.

10. Glaser BG, Strauss AL. The discovery of grounded theory: strategies for qualitative research. New York, NY: Aldine de Gruyter, 1967.

11. Kleinman A. Deep China: the moral life of the person: what anthropology and psychiatry tell us about China today. Berkeley: University of California Press, 2011.

12. Kleinman A. What really matters: living a moral life amidst uncertainty and danger. Oxford, New York: Oxford University Press, 2006.

13. Hui EC. The contemporary healthcare crisis in China and the role of medical professionalism. J Med Philos 2010;35:477-92.

14. Li D, Lu J. A review of studies on doctor-patient trust relationship in China. Chin Med Ethics 2012;25.

15. Corbie-Smith G, Thomas SB, St George DM. Distrust, race, and research. Arch Intern Med 2002;162:2458-63.

16. Guadagnolo BA, Cina $K$, Helbig $P$, et al. Medical mistrust and less satisfaction with health care among Native Americans presenting for cancer treatment. $J$ Health Care Poor Underserved 2009;20:210-26.

17. Gilson L. Trust in health care: theoretical perspectives and research needs. J Health Organ Manag 2006;20:359-75.

18. Mirza NM, Amjad Al, Bhatti AB, et al. Violence and abuse faced by junior physicians in the emergency department from patients and their caretakers: a nationwide study from Pakistan. J Emerg Med 2012;42:727-33.

19. Baidya M, Gopichandran V, Kosalram K. Patient-physician trust among adults of rural Tamil Nadu: a community-based survey. $J$ Postgrad Med 2014;60:21-6.

20. Jacobs EA, Rolle I, Ferrans CE, et al. Understanding African Americans' views of the trustworthiness of physicians. J Gen Intern Med 2006;21:642-7.

21. Kassirer JP. Commercialism and medicine: an overview. Camb Q Healthc Ethics 2007;16:377-86; discussion 439-42.

22. Grande D, Shea JA, Armstrong K. Pharmaceutical industry gifts to physicians: patient beliefs and trust in physicians and the health care system. J Gen Intern Med 2012;27:274-9.

23. Working Party of the Royal College of Physicians. Doctors in society. Medical professionalism in a changing world. Clin Med 2005;5(6 Suppl 1):S5-40.

24. Ding $\mathrm{H}$, Sun $\mathrm{X}$, Chang WW, et al. A comparison of job satisfaction of community health workers before and after local comprehensive medical care reform: a typical field investigation in Central China. PLOS ONE 2013;8:e73438.

25. Ran LM, Luo KJ, Wu YC, et al. An analysis of China's physician salary payment system. J Huazhong Univ Sci Technolog Med Sci 2013;33:309-14.

26. National Commission on Family Planning and Health Announces Patient and Doctors Both Sign. "Do Not Give or Receive" Red Packet Agreements. Secondary National Commission on Family Planning and Health Announces Patient and Doctors Both Sign "Do Not Give or Receive" Red Packet Agreements, 2014. http://www.nhfpc.gov.cn/ yzygi/s3577/201402/b7f939aeaeee41c28ba80023b74c4187.shtml

27. Karnieli-Miller O, Frankel RM, Inui TS. Cloak of compassion, or evidence of elitism? An empirical analysis of white coat ceremonies. Med Educ 2013;47:97-108.

28. Karnieli-Miller O, Vu TR, Frankel RM, et al. Which experiences in the hidden curriculum teach students about professionalism? Acad Med 2011;86:369-77.

29. Swick HM, Szenas P, Danoff D, et al. Teaching professionalism in undergraduate medical education. JAMA 1999;282:830-2.

30. Dossett ML, Kohatsu W, Nunley W, et al. A medical student elective promoting humanism, communication skills, complementary and alternative medicine and physician self-care: an evaluation of the 
HEART program. Explore 2013;9:292-8.

31. Cheng TM. A pilot project using evidence-based clinical pathways and payment reform in China's rural hospitals shows early success. Health Aff (Millwood) 2013;32:963-73.

32. Huang Y. China's doctors are under attack. New York: Hayley Romer, Atlantic Monthly, 2013.

33. Huang Y. Governing health in contemporary China. New York: Routledge, 2013.

34. Holmes M. Students and teachers of the new China: thirteen interviews. Jefferson, NC: McFarland \& Co., 2008.

35. Hamilton GG. Asian business networks. Berlin: Walter de Gruyter, 1996.
36. Li L. Distrust in Government Leaders, demand for leadership change, and preference for popular elections in rural China. Polit Behav 2011;33:291-311.

37. Guan N, Fan Q, Ding J, et al. Melamine-contaminated powdered formula and urolithiasis in young children. $N$ Engl $\mathrm{J}$ Med 2009;360:1067-74.

38. Liebman BL. Malpractice mobs: medical dispute resolution in China. Columbia Law Rev 2013;113:181-264.

39. Juan S, Qian W. Deputy's proposal wins Xi's approval. China Daily 10 March 2014

40. Tucker JD, Nie J, Cheng Y, et al. Reviving medicine as the art of humanity in China. Lancet 2014;383:1462-3. 